Research Article

\title{
Simulation and Analysis with Wavelet Transform Technique and the Vibration Characteristics for Early Revealing of Cracks in Structures
}

\author{
Nidal H. Abu-Hamdeh, ${ }^{1}$ Khaled Daqrouq, ${ }^{2}$ and Fateh Mebarek-Oudina ${ }^{3}{ }^{3}$ \\ ${ }^{1}$ Mechanical Engineering Department, King Abdulaziz University, P. O. Box 80204, Postal Code 21589, Jeddah, Saudi Arabia \\ ${ }^{2}$ Electrical and Computer Engineering Department, King Abdulaziz University, P. O. Box 80204, Jeddah, Saudi Arabia \\ ${ }^{3}$ Department of Physics, Faculty of Sciences, University of 20 août 1955-Skikda, B. P 26 Road El-Hadaiek, Skikda 21000, Algeria
}

Correspondence should be addressed to Fateh Mebarek-Oudina; oudina2003@yahoo.fr

Received 23 October 2020; Revised 31 October 2020; Accepted 10 November 2020; Published 17 February 2021

Academic Editor: Hijaz Ahmad

Copyright (C) 2021 Nidal H. Abu-Hamdeh et al. This is an open access article distributed under the Creative Commons Attribution License, which permits unrestricted use, distribution, and reproduction in any medium, provided the original work is properly cited.

\begin{abstract}
Implementation of improved instruments is used to detect damage in an accurate manner and fully analyze its characteristics. An aluminum beam has been used in this work to identify cracks by using a vibration technique. The simulation of frequency response feature was conducted using a finite element model to provide average measures of intensities of vibration. Two forms of wavelet packet transform (WPT) entropies Shannon and log energy were applied to identify the position, width, and size of the crack. The results showed that with an increase in crack depth, the amplitude also increased at certain crack sizes and for all crack positions. For two crack depths of $1.6 \mathrm{~mm}$ and $0.16 \mathrm{~mm}$ having the same crack size and position $12 \mathrm{~mm}$ and $60 \mathrm{~mm}$, respectively, a $4.5 \%$ increase in amplitude was observed at a crack depth of $1.6 \mathrm{~mm}$. Moreover, the amplitude varied inversely with the position. A $12.6 \%$ increase in amplitude was observed at a crack depth of $1.6 \mathrm{~mm}$ rather than $0.16 \mathrm{~mm}$, while both depths occurred at the same crack position $(75 \mathrm{~mm})$ and size $(20 \mathrm{~mm})$. Experimental validation was performed on a cantilever beam with one crack. The maximum absolute error found was $7.5 \%$ for the crack position and $9.1 \%$ for the crack size. With the increase in crack depth, the obtained results decrease the stiffness of a beam in a single crack case.
\end{abstract}

\section{Introduction}

The process of crack detection in civil engineering and mechanical systems structures have gained the attention of majority of the researchers in the last two decades [1-3]. Majority of nondestructive methods were used on the basis of the modifications in the properties of dynamic structures for detecting cracks. Previously, Pandey et al. [4] implemented the mode size and shape curvature for detecting crack damages. The curvature of mode in the place of damage increased with the mitigation in cross section due to the deterioration. Parloo et al. [5] have explained independent damage detection methods by undertaking modal parameters. The frequency domain maximum likelihood estimator method was used to detect the changes made in the mode size and shape of slat track occurred due to the crack damages. By proposing a modal analysis approach, Khoo et al. [6] monitored the presence of cracks in a wooden wall structure. The modifications in natural observations were utilized for the detection of the presence of destruction and damage-sensitive modes.

A local flexibility is introduced by a structural crack that can modify the structural dynamic behavior. The requirement of a baseline dataset was based on the intact structure so that some of the destruction index methods can compare the modifications in physical and chemical properties of the stiff beam structure caused by the damage. In particular, the baseline dataset is obtained from the measurement of the undamaged structure. For instance, Sampaio et al. [7] mitigated the standard values of the natural vibration curvature of the deteriorated structure in the presence of intact structure. Recently, the demands for structural inspection 
specifically for the damaged structure have increased. The use of cheap, effective, and fast methods is a privilege in structural health monitoring [8]. It is also considerable for implementing such detection approaches that tend to detect the cracks regardless of the requirement of any standard data of vibration response of an intact structure, including mode shapes and damping and natural frequencies, although several detection frameworks are still utilized effectively $[9,10]$. However, there are limited detection methods that fulfill this aspect such as wavelet transform (WT).

The identification of cracks primarily uses nondestructive test (NDT) techniques on either a structural or a machine part. In this technique, the overall structure has to be checked for identifying a crack $[11,12]$. The use of NDT methods is not economical for beams and pipelines. Additionally, the procedure is monotonous as the use of vibration-based methods is prompted on account of the negative aspects of NDT techniques regarding the detection of structural damage [7]. The fundamental concept behind these techniques is that one of the vibration features of a member appears when a crack is introduced in a member. For instance, the natural frequency and stiffness of the crack are reduced when damping of a member increases [13]. The size and crack location are determined by using the vibration details acquired from different locations in the structure. It is possible that the crack's vicinity and size can be estimated by assessing the modifications in vibration features as changes in crack deformation are mode-dependent.

Cracks have a huge impact on the behavior of structures. Structures undergo periodic inspection to ensure that they are safe. Therefore, this study develops a technique to use the variation in the forced vibration amplitude for checking the presence of multiple cracks. Afterwards, a numerical solution is proposed based on the finite element analysis using ANSYS program. Different crack positions were taken into account for determining the solution based on vibration equation for each element. The effects of mode shape data and crack location were examined for verifying the practicability and usability of the developed method. The simulated and experimental findings reveal that the developed method has a maximum practicability in the domain of detecting cracks of long pipelines and beams and can, therefore, be suggested for practical applications. The first contribution in this study is the use of wavelet transform that can decompose the signal into different band passes of frequency, so that we can work on the specific band pass of frequency of interest. The second contribution is the use of entropy that makes the results very specific based only on one number. The third contribution is the use of the waveletentropy combination, which is used for the first time in detecting cracks in beams. This research is expected to open new doors for utilizing the wavelet transform technology in the structural mechanics and composites communities.

\section{Related Work}

Since substantial variation in a member's behavior occurs due to the existence of cracks, additional behavioral observation is required, and such observation ensures the continuous operation of the member. Therefore, vibrationbased monitoring of members in service with crack-like defects is very essential and, subsequently, much attention has been given to the analysis of vibration of members with cracks or crack-like defects. Non-standard elasticity is produced by cracks produced within the beam structure, affecting its dynamic behavior; for instance, it changes the mode shapes and decreases the natural frequencies. Crack detection can be achieved by analyzing these effects [14]. Dimarogonas [15] developed a crack model based on local flexibility and utilized fracture mechanics to calculate the equivalent stiffness. He introduced a technique for predicting the depth and vicinity of a crack experimentally on the basis of variations in standard observations. Patil and Maiti [16] introduced a technique to predict the size and vicinity of several different cracks on the basis of measurement of standard observations. Shen and Taylor [17] also introduced an approach for identifying beam cracks in a Euler-Bernoulli beam on the basis of minimized differences.

Masoud et al. [18] carried out a vibrational investigation to detect symmetric cracks in a fixed-fixed beam, taking into account the connecting effect of the axial load and crack depth. Liang et al. [19] detected cracks in fixed-fixed and beam structures on the basis of changes in amplitudes and standard observations. Narkis [20] has used an approximate analytical solution to compute the standard observations of a cracked cantilever beam. Narkis [20] concluded that the variation in the initial standard observations caused by the crack is the only information required. Dado [21] detected the crack depth and location with respect to predefined beam structures with the help of a direct mathematical model for detecting beam cracks where the standard observations were used as input observations for the first two bending vibration modes. Hu and Liang [22] used the spring damage model to identify the size and location of a crack in a damaged element. Baviskar and Tungikar [23] established a systematic technique for identifying crack features by measuring natural frequencies with the help of artificial neural networks (ANNs). They observed variations in standard observations for the first five modes, as they were predominant in crack properties. They also observed a greater frequency reduction at crack locations away from the support because of the stiffness of the structure and the consequent suppression of vibrations near the support. Kisa et al. [24] applied the finite element model and component mode synthesis to investigate the vibration features of a cracked Timoshenko beam. A flexibility matrix divides the team into subparts by applying the interaction forces. Fischer and Beltz [25] showed that there is a considerable impact of crack geometry on the fracture behavior of the material.

Recently, several studies have been conducted on multicrack recognition of several structures. Sekhar [26] has summarized various studies on multicracks and explained the identification methods and their respective impacts on vibration structures such as rotors, beams, and pipes. Mazanoglu et al. [27] have conducted a vibrational analysis of nonuniform beams with multiple cracks by using the Rayleigh-Ritz approximation method to explore the effects of axial force levels and cracks on eigenfrequencies. Khiem 
and Lien [28] proposed a new method for investigating the frequency of natural beams with an arbitrary number of cracks by using a transfer matrix. Using Ritz approximation, Banerjee et al. [29] studied the impact of an open transverse crack on the higher and natural order free vibration modes of an isotropic beam. Ahmad et al. [30] used curvature mode shapes along with filtering technique that involved the gapped smoothing method for obtaining better results regarding the detection of multiple occurrences of damage in the plate structure. Khalkar and Ramachandran [31] have performed modal analysis by using ANSYS software for identifying the natural observations of different rectangular shape and v-shape subjects of a cantilever cracked beam.

Dahak et al. [32] used the standard observations for quantifying and localizing beams' cracks. Hanif et al. [33] have addressed the challenges in vibration modeling on concrete modeling by implementing nonlinear behavior. Erdogan [8] investigated the nonlinear dynamics of cracked beams by using the linear properties of nonlinear vibrating structures to extend the crack detection mechanisms. Matsko et al. [34] have presented an investigation of cracked beam forced oscillations for identifying random procedures correlated periodically with the use of statistical methods. For the first time, Prawin et al. [35] identified the pure spatial location of the breathing crack using a single sensor measurement based on a new vibration-based damage detection technique, which relies on the zero strain energy nodes concept. Jiang et al. [36] have employed proper orthogonal decomposition (POD) for developing a damage location method for beam-like structures. The researchers have utilized POD for acquiring the approximate direction of optimized nonlinear systems and for identifying the vicinity of maximal changes in damaged and undamaged beam structures. Maurya et al. [37] have presented a study to predict the occurrence of several different cracks in a cantilever beam by using ANN. By using frequency response function estimation, Padil et al. [38] have detected damages in the presence of artificial neural network (ANN). Teng et al. [39] have studied the evolution of localized crack growth by introducing an acoustic data-driven deviation detection method based on statistical probability models called the consensus self-organizing models (COSMO). De Lellis et al. [40] have computed perturbation parameters associated with structural impairments by applying a classic Craig-Bampton Approach version's stochastic version. The researchers have argued that this method can be constructed as an optimization black box technique for enhancing the model correlating with investigated data with the use of the finite element model. Choi and Han [41] have proposed a method for damage detection by using vision-based monitoring with the motion magnification technique.

Wavelet transform is a very well-defined method for recognition. The entropy measure has gained the attention of many researchers on account of its ability to distinguish data in a very sharp and elegant manner. Therefore, wavelet entropy has been used for the detection of signatures, speech signals, or pathological models of diseases [42, 43]. Chang and Chen [44] have established an intensity factor to identify the correlation of the cracks size to the wavelet transform coefficients in order to estimate the relative depth of cracks. Chang et al. [45] have calculated the natural frequencies and mode shapes of multiple cracked beams under free vibration. They used wavelet transformation to analyze the mode shapes and to obtain the positions of the cracks. Findings indicated that it was efficient to use continuous wavelet transformation than discrete wavelet transformation. This is because continuous wavelet transformation offers a more precise resolution, which is necessary to find the damage. Zamanian and Ohadi [46] presented a modified technique used for crack detection that requires less computational effort in comparison with the conventional methods Gómez et al. [47] integrated vibration signal analysis for detecting real railway installed cracks on working bogie. The WPT energy was used to process vibration signals.

2.1. Orthogonal Wavelet Function. Wavelet packet bases are calculated for a right orthogonal wavelet function family. A particular method for decomposing data was offered by each of these wavelet bases where the data energy was preserved and the exact features can be reconstructed. In this study, the WPT has been used for feature extraction of the vibration frequency and for identifying whether the elicited wavelet data are of a great length [48]. From the published literature, it was identified that the use of entropy over the WPT subsignals is very effective for extracting the features for recognition tasks. For example, Souani et al. [49] tested an algorithm to determine its ability for computing the wavelet norm's entropy value in digital module. In this reference, Ghaffari et al. [50] used the genetic algorithm and WPT to carry out pathological assessment, where the energy characteristics were calculated from a set of wavelet packet subsignals. An adaptive network-based fuzzy system with wavelet packet entropy was created for the classification of 20 textural images taken from the Brodatz image album [51]. Another paper [2] suggested a classification system for speaker identification using an amalgamation of three types of entropy (sure, logarithmic energy, and norm). The study of Avci [52], on the other hand, suggested the use of wavelet features by the energy and entropy extractor and an ANFIS classifier.

The entropy taken over subbands of the wavelet transform can be utilized as features for data recognition tasks. In this study, the entropy obtained from WPT created feature vectors with a small length which benefited the vibration frequency classification process. This approach greatly assisted in identifying positions, depths, and sizes of different cracks.

The wavelet packet transform offers a richer decomposition coefficient for better classification performance. The wavelet transform is described as the inner product of the data $x(t)$ with the mother wavelet $\psi(t)$ [43]:

$$
\begin{aligned}
\Psi_{a, b}(t) & =\Psi\left(\frac{t-b}{a}\right), \\
W_{\Psi} x(a, b) & =\frac{1}{\sqrt{a}} \int_{-\infty}^{+\infty} x(t) \Psi *\left(\frac{t-b}{a}\right) \mathrm{d} t .
\end{aligned}
$$


Here, $a$ and $b$ are the scale and shift parameters, respectively. The symbol “*” denotes the conjugate version. By calibrating $a$ and $b$, we may get a dilated and translated version of $\Psi(t)$.

Data were recursively decomposed through the WPT by using the recursive binary tree. Generally, the WPT is very similar to the discrete wavelet transform (DWT), but it decomposes both details and approximation coefficients. The wavelet packet generates two sequences with the help of filters to capture extreme frequency subband properties of the input data. A previous node is defined to generate the two-wavelet orthogonal bases:

$$
\begin{gathered}
\Psi_{j+1}^{2 p}(k)=\sum_{n=-\infty}^{\infty} h[n] \Psi_{j}^{p}\left(k-\frac{2}{n}\right), \\
\Psi_{j+1}^{2 p+1}(k)=\sum_{n=-\infty}^{\infty} g[n] \Psi_{j}^{p}\left(k-\frac{2}{n}\right) .
\end{gathered}
$$

Here, $h[n]$ and $g[n]$ represent the low-pass and highpass filters, respectively. $\psi(n)$ represents the wavelet function. Also, $j$ and $p$ are the level and node number of the previous node, respectively [53].

\section{Methodology}

It has been experimentally proven that damages can be detected by measuring changes in the natural frequency. This claim is based on following reasons that support this method [19]:

(i) High accuracy with respect to acquiring of the required features

(ii) Easy determination of the size and depth of cracks

(iii) Suitability for all types of structural damage

The extent of the growth of a crack in any structural element affects the decrease in stiffness of the element, which also results in a decrease in its natural frequency. Several researchers have used this method by applying fundamental vibration measurement tools using an experimental process for determining the resounding observations [51, 54, 55].

3.1. Modeling and Procedure. In this study, the cantilever beam model has been used. The dimensions of the beam are as follows: width $h=64 \mathrm{~mm}$, thickness $b=20 \mathrm{~mm}$, and length from the fixed end $l=360 \mathrm{~mm}$. The beam was assumed to be made of aluminum and had the following properties: Young's modulus $(E)=70 \times 109 \mathrm{~N} / \mathrm{m}^{2}$, Poisson ratio $(\nu)=0.33$, and density $=2700 \mathrm{~kg} / \mathrm{m}^{3}$.

As shown in Figure 1, the cantilever beam prototype was modeled by using the ANSYS program version 15 for the whole model. Due to the efficiency of solving these types of software, we can use them in several technological and industrial fields [56-58]. The dynamic analysis was used to present the fixed support at the left side and a unit force of the beam. At the free beam end, a unit force was applied on the left side of the fixed support.

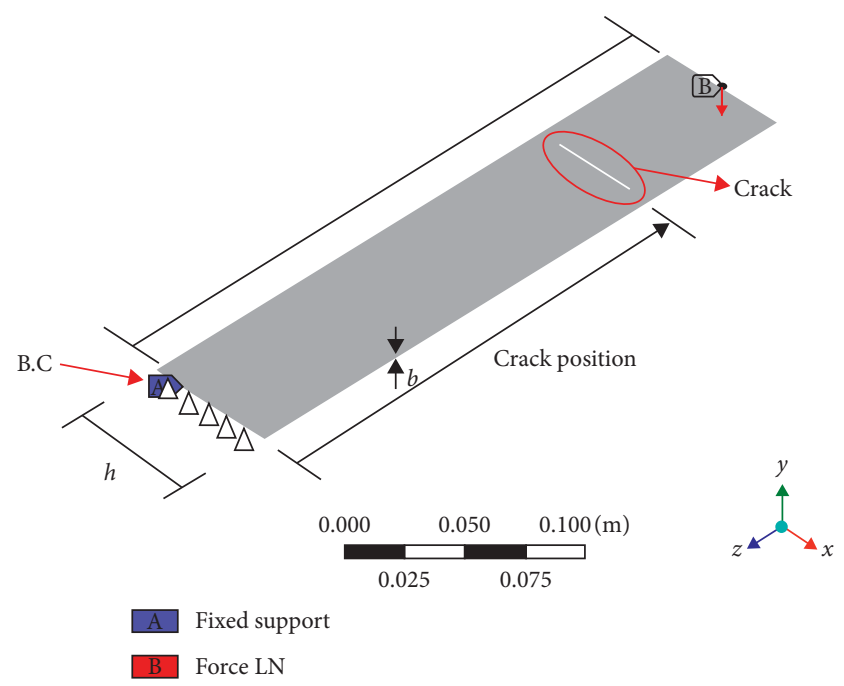

Figure 1: The model beam created by the ANSYS program.

A finite element model was developed with adequate features such as loads, constraints, element type, mesh selection, and dimensions, with the fundamental understanding of its working. A fixed support was considered and implemented at the beam's left end, undertaking the boundary conditions. Several mesh sizes were attempted and 3D tetrahedral elements were used for obtaining the optimum solution with global mesh size of 6 nodes of $2.5 \mathrm{~mm}$ (Figure 2). Different mesh sizes were investigated at the crack, and the best solution was achieved with nodes in a constant radial distribution and a global mesh size of $1 \mathrm{~mm}$. A total of 51363 number of elements were used for the mesh model along with 8920 nodes.

3.2. Simulation of the Procedure. The obtained amplitudes were primarily utilized for the diagnosis procedure. With additional analysis, the identical amplitudes were applied to pinpoint the crack size plus its position. For every case of damaged cantilever beam model, the researcher has undertaken the first three standard observations at higher modes. A single crack occurs at a specific position in every single case of the cracked cantilever beam model. The crack position and size vary with the depth in cracks where different crack vicinities were undertaken at each crack position.

This analysis determined the solution to the vibration equation for each element. If the creation of stiffness matrices that describe and explain the structure's vibration response is required, a combination of the solution to each finite element should be conducted. The node motion of the finite element mesh was represented by displacement connected with the solution. An aluminum beam with precise material properties as shown in the above example was examined. The package of finite elements aided in finding regular frequencies for the cracked and uncracked geometries [59-61].

3.3. Finite Element Analysis. A numerical method which utilizes a variety of interjection systems to tackle and display boundary value problems is known as finite element 


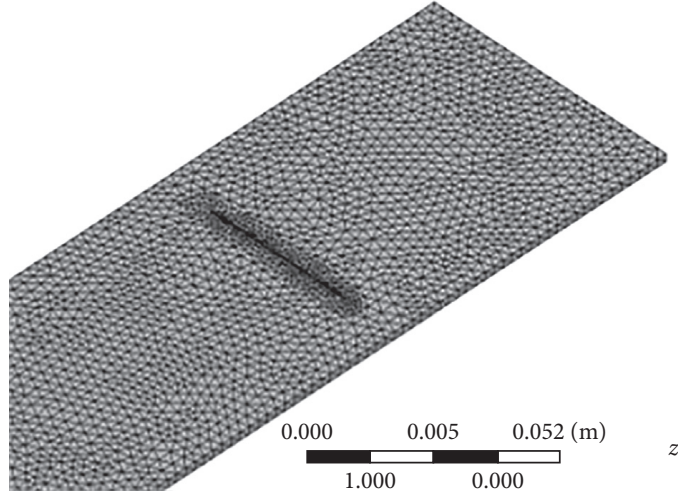

(a)

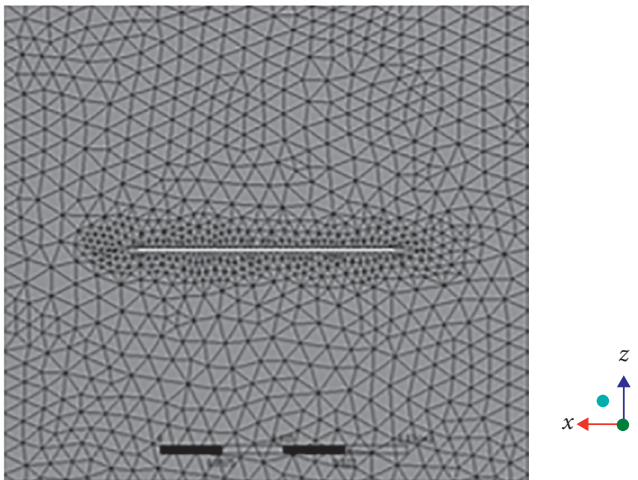

(b)

FIgURE 2: Meshing: (a) beam mesh and (b) mesh at crack.

analysis. It is an effective approach to examine vibrationrelated issues that have specific boundary conditions. The node motion of the finite element mesh was represented by the displacement that was associated with the solution. The package of finite element aided in finding regular frequencies for the cracked and uncracked beams. The beam was discretized with the isoperimetric components of 8 nodes. Twelve quarter-tip particularity components were utilized around the split tip.

3.4. The Geometric Crack. A prismatic-shaped crack was used to study and analyze the effects of the crack geometry (Figure 3). In the figure, symbol " $a$ " represents the size of the crack ( $a=12$ to $20 \mathrm{~mm}$ ) and $L_{c}$ represents the length of the crack $\left(L_{c}=2 a\right)$.

For the crack's dislocation, 1 Newton force was exerted on the crack and equilibrium was accomplished for the slip distribution along the inclined slip plane. A type of aluminum alloy (6082-T6) of $2 \mathrm{~mm}$ thickness was used in the as-received state. In the beginning, a center-cracked beam was assumed and crack growth rate was evaluated by using a 7-point quadratic fit for the data shown in ASTM-E647.

3.5. Wavelet Analysis. This section reveals the wavelet entropy analysis. The vibration frequency vector $\Gamma$ may be represented as follows:

$$
\Gamma=\left\{f_{1}, f_{1}, \ldots, f_{n}\right\},
$$

where $f_{n}$ represents a vibration frequency sample of a given depth or size.

The WPT subsignals are as follows:

$$
M_{\mathrm{WPT}}=\left[c_{1}, c_{2}, c_{3}, \ldots, c_{H}\right],
$$

where $c_{H}$ is the WPT node and $h=1,2, \ldots, H$; $H$ represents the number of wavelet packet transform nodes. In the next step, the entropy should be evaluated for $M_{\mathrm{WPT}}$. To achieve a better performance, different types of entropies were tested.

The nonnormalized Shannon entropy is given by

$$
E(s)=-\sum s_{\tau}^{2} \log \left(s_{\tau}^{2}\right) .
$$

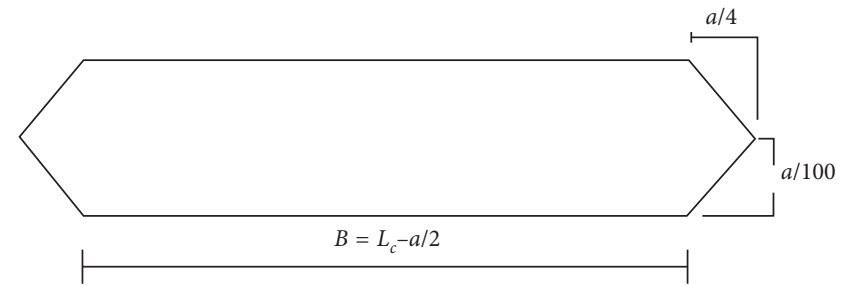

FIgURE 3: Geometric crack.

The log energy entropy is given by

$$
E(s)=\sum_{\tau} \log \left(s_{\tau}^{2}\right)
$$

The input data were the frequency measurements and $s_{i}$ represents the coefficients of $s$ on orthonormal basis. The obtained entropy results were the feature outputs of the vibration frequency of the given parameter.

\section{Experimental Study}

The accuracy and effectiveness of the cantilever beams were verified through an experiment. A minimal crack location was differentiated through the cracked mode shapes and the subsequent uncracked beams.

Specimens were made of aluminum. The material properties were as follows: modulus of elasticity $(\epsilon)=70 \mathrm{GPa}$ and mass density $(\rho)=2700 \mathrm{~kg} / \mathrm{m}^{3}$. Different crack positions and sizes were examined by wire cut machining. A readymade fixture was utilized comprising of a heavy base plate to clamp a specimen. Figure 4 presents the overall experimental setup. The wax was used to fix the accelerometer (Bruel and Kjaer, Type 4344) with a mass of $2 \mathrm{~g}$ on the beam's top edge. A charge amplifier (Bruel and Kjaer, Type 5974) supplies the accelerator's output. An FFT analyzer (Tektronix TDS 220) investigates the charge amplifier output. A digital readout was generated by the analyzer for the observational peaks. A specimen was slightly tapped by an instrument in the crosswise direction throughout the examination procedure. The FFR analyzer was also used to test the beam response. The first initial natural observations were reported from the frequencies. 


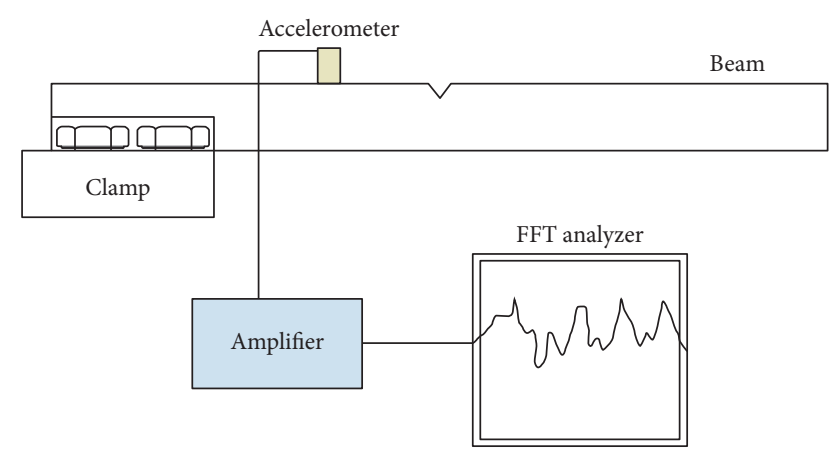

FIgURE 4: Experimental setup.

\section{Results and Discussion}

As shown in Table 1, the relationship between the crack's position from the beam's fixed end and its effects on the frequency intensity was investigated for physical, chemical, and harmonic frequencies. The association between the frequency propagation and crack's depth was identified from the responses. The depth's function occurred due to the changes in frequency caused by this association. Clearly, the fundamental frequency decreases significantly as shown by elevation in the crack depth. The highest crack depth undergoes the greatest decrease in frequency because the removed material causes a reduction in the beam's stiffness and hence the natural frequency. The location of the crack from the fixed end certainly affects the extent of the decrease in the frequency as the depth of the crack increases. The farther is the crack location from the fixed end, the smaller is the decrease in the frequency at equivalent depths. Comparing the closest and farthest locations, the crack was felt more at the $60 \mathrm{~mm}$ location than the $200 \mathrm{~mm}$ location.

For detecting and distinguishing various crack positions of a $12 \mathrm{~mm}$ crack, the results of wavelet Shannon entropy (WSHE) and wavelet log energy entropy (WLEE) of the vibration frequency for different depths and positions were calculated (Table 1). The results showed the possibility of positional recognition by WSHE and WLEE, where each value of the entropy presents the position accurately. The results of WSHE and WLEE of the frequency for a $12 \mathrm{~mm}$ crack at different vicinities and depths for each position are illustrated in Figures 5 and 6, respectively. The values of both WSHE and WLEE accurately distinguished the modal and harmonic characteristics. The entropy values easily separated each position accurately for both modal and harmonic characteristics.

Table 2 shows the findings of the vibration frequency obtained for the modal and harmonic manners at various positions and depths with a $16 \mathrm{~mm}$ crack. The overall frequencies decreased significantly in comparison with the corresponding values shown in Table 1 on account of an increase in crack size from 12 to $16 \mathrm{~mm}$. To detect and distinguish various crack positions for the $16 \mathrm{~mm}$ crack, the results of WSHE and WLEE for the vibration frequency assessed for different depth positions were calculated ( $\mathrm{Ta}-$ ble 2). The results show the possibility of positional recognition by WSHE and WLEE, where each value of the entropy presented the position accurately. The results of both modal and harmonic characteristics were tabulated. The wavelet entropies calculated for the $12 \mathrm{~mm}$ crack can be easily differentiated from those calculated for the $16 \mathrm{~mm}$ crack.

The WSHE and WLEE results for the frequency of a $16 \mathrm{~mm}$ crack at different positions and depths are illustrated in Figures 7 and 8, respectively. The values of both WSHE and WLEE can accurately distinguish the modal and harmonic characteristics. The entropy values could easily separate each position accurately for both modal and harmonic characteristics. When the results obtained for both crack sizes were compared, the wavelet entropies calculated for the $12 \mathrm{~mm}$ crack were found to be different from those calculated for the $16 \mathrm{~mm}$ crack.

Table 3 shows the outcomes for an $18 \mathrm{~mm}$ crack at various positions and various depths. A noteworthy reduction was observed in the overall frequency when the results were compared to the corresponding values shown in Table 2, on account of increase in the crack size from 16 to $18 \mathrm{~mm}$. The frequency further decreased as the crack size increased. To detect and distinguish various crack positions of the $18 \mathrm{~mm}$ crack, the WSHE and WLEE vibration frequency results were calculated for different depths and positions as shown in Table 3. The results showed the possibility of positional recognition by WSHE and WLEE, where each value of the entropy presented the position of the crack accurately. From the results obtained, the wavelet entropies calculated for the $12 \mathrm{~mm}$ crack can be easily distinguished from those calculated for $16 \mathrm{~mm}$ and $18 \mathrm{~mm}$ cracks.

The WSHE and WLEE results for the frequency for an $18 \mathrm{~mm}$ crack at different positions and different depths are illustrated in Figures 9 and 10, respectively. The values of both WSHE and WLEE accurately distinguish the modal and harmonic characteristics. The entropy values easily separated each position accurately for both modal and harmonic characteristics. When the results obtained for previous crack sizes were compared, the wavelet entropies calculated for the $12 \mathrm{~mm}$ crack size were different from those calculated for the $16 \mathrm{~mm}$ and $18 \mathrm{~mm}$ crack.

Table 4 presents findings of amplitude and observation for a cracked beam with various crack sizes and depths at a fixed crack position $75 \mathrm{~mm}$. The results showed that the crack size was affected by both the frequency and amplitude of vibration. In terms of the amplitude, it increased significantly as the crack size increased through the depth range of 1.6 to $16 \mathrm{~mm}$. This result can be explained by the way that the crack direction triggers flexibility in the member, whereby an increase in crack size from 12 to $20 \mathrm{~mm}$ resulted in an increase in flexibility, hence increasing the amplitude of vibration. To detect and distinguish various crack sizes for a fixed crack position of $75 \mathrm{~mm}$, the WSHE and WLEE results for the vibration frequency assessed for different depths at each crack size were calculated (Table 4). The results showed the possibility of size recognition by WSHE and WLEE, as the size was accurately determined using each entropy value.

The WSHE and WLEE results of the frequency for various crack sizes and at different depths at a fixed crack 
TABLE 1: The results of the wavelet Shannon entropy (WSHE) and wavelet log energy entropy (WLEE) of the vibration frequency calculated for different depths and positions of a $12 \mathrm{~mm}$ crack.

\begin{tabular}{|c|c|c|c|c|c|c|}
\hline \multirow{2}{*}{ Position (mm) } & \multicolumn{3}{|c|}{ Modal } & \multicolumn{3}{|c|}{ Harmonic } \\
\hline & Depth (mm) & Frequency $(\mathrm{Hz})$ & WSHE/WLEE & Amplitude (mm) & Frequency $(\mathrm{Hz})$ & WSHE/WLEE \\
\hline \multirow{7}{*}{60} & 1.6 & 14.786 & - & 39.214 & 14.78 & - \\
\hline & 3.2 & 14.775 & $-8.1512 e+03$ & 39.264 & 14.77 & $-8.0779 e+03$ \\
\hline & 4.8 & 14.761 & & 39.336 & 14.76 & 37.5899 \\
\hline & 11.2 & 14.644 & & 39.924 & 14.64 & \\
\hline & 12.8 & 14.619 & & 40.049 & 14.61 & \\
\hline & 14.4 & 14.612 & & 40.087 & 14.61 & \\
\hline & 16.0 & 14.441 & & 40.981 & 14.44 & \\
\hline \multirow{7}{*}{100} & 1.6 & 14.787 & - & 39.210 & 14.78 & - \\
\hline & 3.2 & 14.781 & $-8.2387 e+03$ & 39.246 & 14.78 & $-8.1467 e+03$ \\
\hline & 4.8 & 14.772 & 37.7072 & 39.299 & 14.77 & 37.6406 \\
\hline & 11.2 & 14.704 & & 39.713 & 14.7 & \\
\hline & 12.8 & 14.690 & & 39.799 & 14.69 & \\
\hline & 14.4 & 14.686 & & 39.825 & 14.68 & \\
\hline & 16.0 & 14.584 & & 40.461 & 14.58 & \\
\hline \multirow{7}{*}{120} & 1.6 & 14.787 & - & 39.209 & 14.78 & - \\
\hline & 3.2 & 14.783 & $-8.1787 e+03$ & 39.237 & 14.78 & $-8.1710 e+03$ \\
\hline & 4.8 & 14.777 & 37.6639 & 39.279 & 14.77 & 37.6583 \\
\hline & 11.2 & 14.729 & & 39.613 & 14.72 & \\
\hline & 12.8 & 14.718 & & 39.685 & 14.71 & \\
\hline & 14.4 & 14.715 & & 39.704 & 14.71 & \\
\hline & 16.0 & 14.642 & & 40.215 & 14.64 & \\
\hline \multirow{7}{*}{160} & 1.6 & 14.788 & - & 39.205 & 14.78 & - \\
\hline & 3.2 & 14.786 & $-8.2187 e+03$ & 39.222 & 14.78 & $-8.2104 e+03$ \\
\hline & 4.8 & 14.784 & 37.6928 & 39.245 & 14.78 & 37.6869 \\
\hline & 11.2 & 14.763 & & 39.438 & 14.76 & \\
\hline & 12.8 & 14.759 & & 39.478 & 14.75 & \\
\hline & 14.4 & 14.758 & & 39.491 & 14.75 & \\
\hline & 16.0 & 14.726 & & 39.785 & 14.72 & \\
\hline \multirow{7}{*}{200} & 1.6 & 14.788 & - & 39.203 & 14.78 & - \\
\hline & 3.2 & 14.788 & $-8.2404 e+03$ & 39.210 & 14.78 & $-8.2349 e+03$ \\
\hline & 4.8 & 14.788 & 37.7084 & 39.220 & 14.78 & 37.7045 \\
\hline & 11.2 & 14.782 & & 39.306 & 14.78 & \\
\hline & 12.8 & 14.781 & & 39.324 & 14.78 & \\
\hline & 14.4 & 14.781 & & 39.330 & 14.78 & \\
\hline & 16.0 & 14.771 & & 39.462 & 14.77 & \\
\hline
\end{tabular}

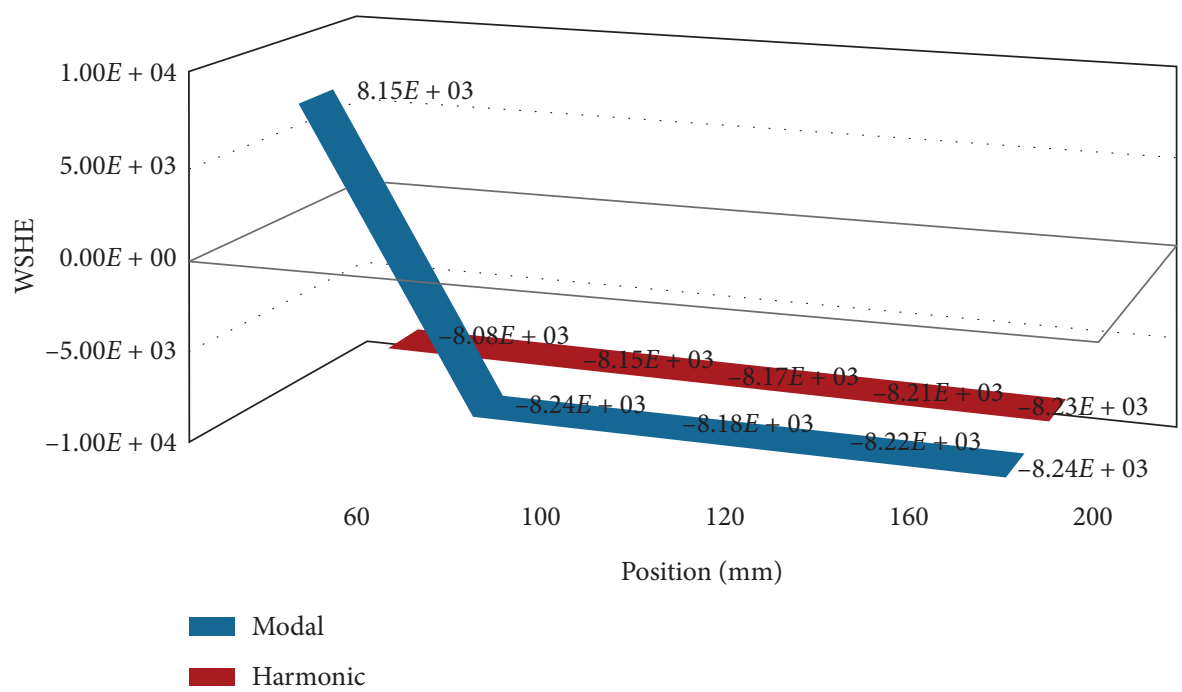

Figure 5: The results of the WSHE of the frequency for a crack size of $12 \mathrm{~mm}$ at different positions and different depths. 


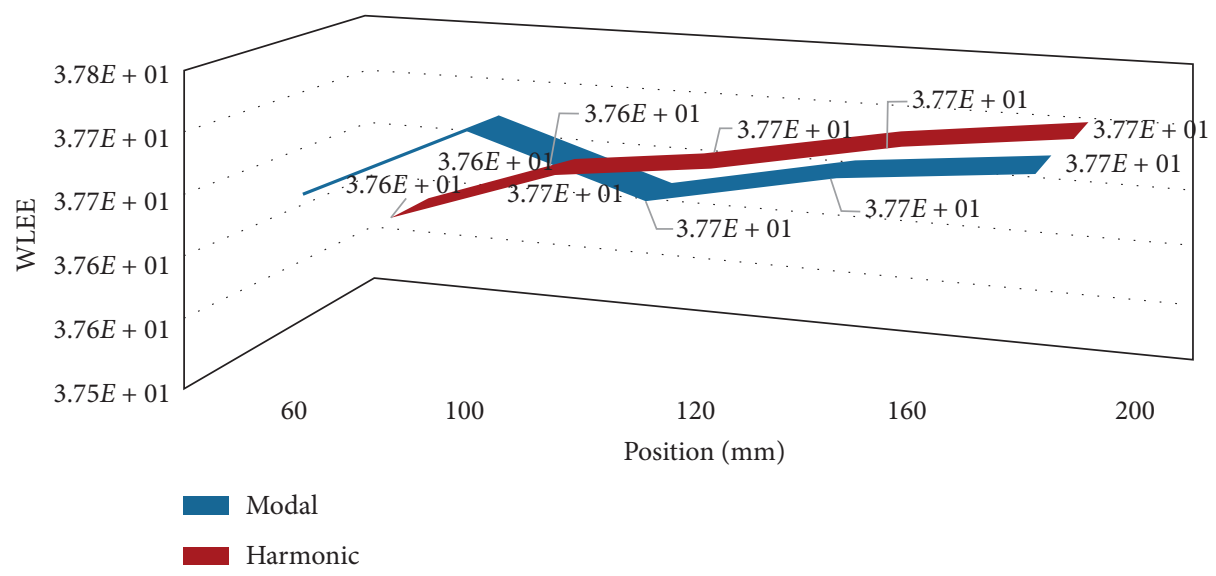

FIgURE 6: The results of the WLEE of the frequency for a crack size of $12 \mathrm{~mm}$ at different positions and different depths.

TABLE 2: The results of the WSHE and WLEE of the vibration frequency calculated for different depths and positions of a $16 \mathrm{~mm}$ crack.

\begin{tabular}{|c|c|c|c|c|c|c|}
\hline \multirow{2}{*}{ Position (mm) } & \multicolumn{3}{|c|}{ Modal } & \multicolumn{3}{|c|}{ Harmonic } \\
\hline & Depth $(\mathrm{mm})$ & Frequency $(\mathrm{Hz})$ & WSHE/WLEE & Amplitude (mm) & Frequency $(\mathrm{Hz})$ & WSHE/WLEE \\
\hline \multirow{7}{*}{60} & 1.6 & 14.784 & - & 39.224 & 14.78 & - \\
\hline & 3.2 & 14.769 & $-7.9592 e+03$ & 39.294 & 14.76 & $-8.2345 e+03$ \\
\hline & 4.8 & 14.747 & 37.5002 & 39.403 & 14.74 & 37.7042 \\
\hline & 11.2 & 14.544 & & 40.438 & 14.54 & \\
\hline & 12.8 & 14.490 & & 40.720 & 14.49 & \\
\hline & 14.4 & 14.468 & & 40.836 & 14.46 & \\
\hline & 16.0 & 14.160 & & 42.509 & 14.16 & \\
\hline \multirow{7}{*}{100} & 1.6 & 14.786 & - & 39.217 & 14.78 & - \\
\hline & 3.2 & 14.778 & $-8.0777 e+03$ & 39.265 & 14.77 & $-8.0706 e+03$ \\
\hline & 4.8 & 14.765 & 37.5896 & 39.344 & 14.76 & 37.5844 \\
\hline & 11.2 & 14.647 & & 40.071 & 14.64 & \\
\hline & 12.8 & 14.613 & & 40.278 & 14.61 & \\
\hline & 14.4 & 14.602 & & 40.351 & 14.60 & \\
\hline & 16.0 & 14.417 & & 41.529 & 14.41 & \\
\hline \multirow{7}{*}{120} & 1.6 & 14.786 & - & 39.214 & 14.78 & - \\
\hline & 3.2 & 14.781 & $-8.1961 e+03$ & 39.253 & 14.78 & $-8.1206 e+03$ \\
\hline & 4.8 & 14.772 & 37.6765 & 39.315 & 14.77 & 37.6214 \\
\hline & 11.2 & 14.687 & & 39.903 & 14.68 & \\
\hline & 12.8 & 14.664 & & 40.065 & 14.66 & \\
\hline & 14.4 & 14.655 & & 40.126 & 14.65 & \\
\hline & 16.0 & 14.521 & & 41.075 & 14.52 & \\
\hline \multirow{7}{*}{160} & 1.6 & 14.788 & - & 39.207 & 14.78 & - \\
\hline & 3.2 & 14.786 & $-8.0777 e+03$ & 39.230 & 14.78 & $-8.1897 e+03$ \\
\hline & 4.8 & 14.782 & 37.5896 & 39.266 & 14.78 & 37.6719 \\
\hline & 11.2 & 14.746 & & 39.605 & 14.74 & \\
\hline & 12.8 & 14.736 & & 39.697 & 14.73 & \\
\hline & 14.4 & 14.732 & & 39.735 & 14.73 & \\
\hline & 16.0 & 14.674 & & 40.281 & 14.67 & \\
\hline \multirow{7}{*}{200} & 1.6 & 14.788 & - & 39.204 & 14.78 & - \\
\hline & 3.2 & 14.788 & $-8.2345 e+03$ & 39.213 & 14.78 & $-8.2255 e+03$ \\
\hline & 4.8 & 14.787 & 37.7042 & 39.230 & 14.78 & 37.6977 \\
\hline & 11.2 & 14.778 & & 39.382 & 14.77 & \\
\hline & 12.8 & 14.775 & & 39.423 & 14.77 & \\
\hline & 14.4 & 14.775 & & 39.439 & 14.77 & \\
\hline & 16.0 & 14.757 & & 39.684 & 14.75 & \\
\hline
\end{tabular}




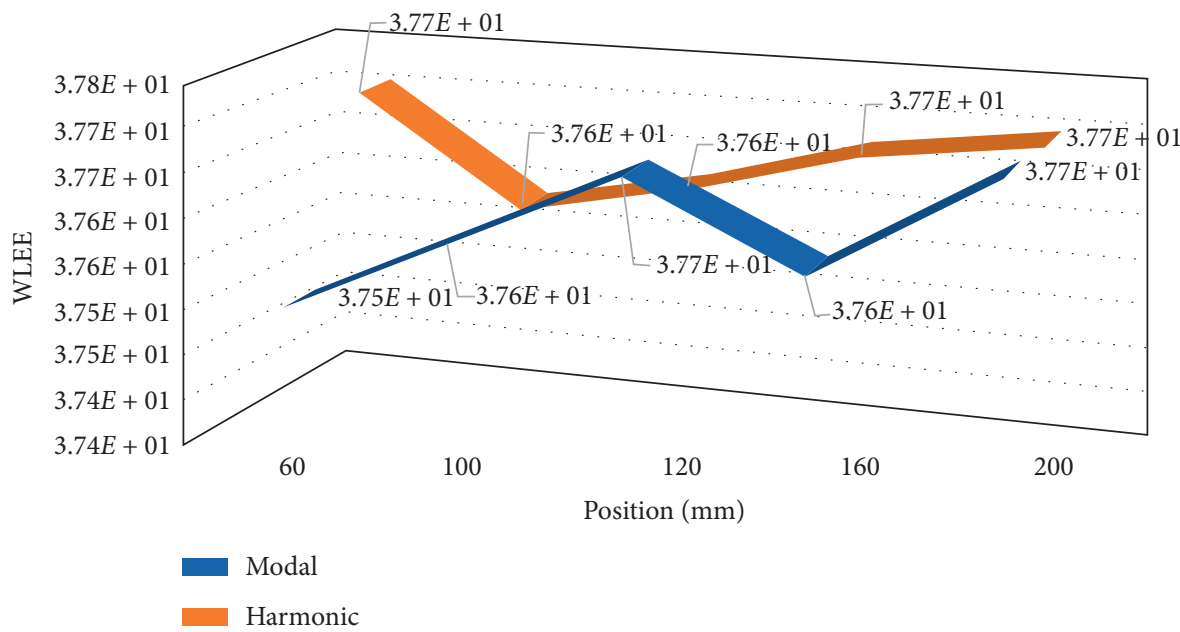

Figure 7: The results of the WLEE of the frequency for a crack size of $16 \mathrm{~mm}$ at different positions and different depths.

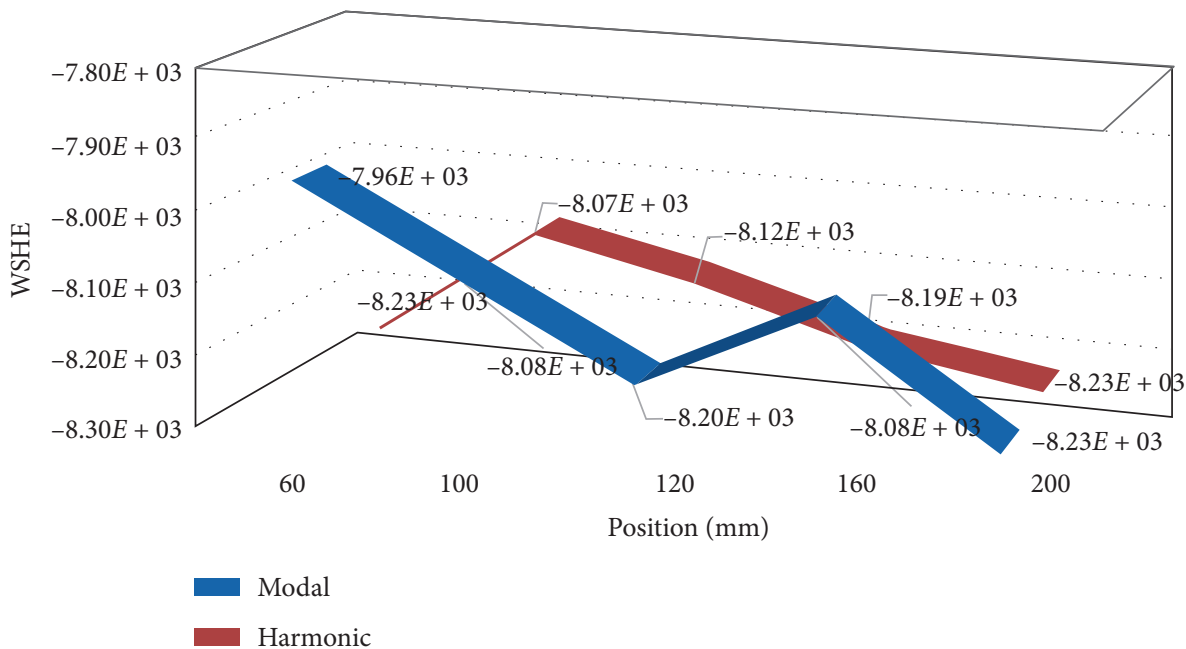

FIGURE 8: The results of the WSHE of the frequency for a crack size of $16 \mathrm{~mm}$ at different positions and different depths for each position.

position of $75 \mathrm{~mm}$ are illustrated in Figures 11 and 12, respectively. The values of both WSHE and WLEE accurately distinguished the modal and harmonic characteristics. The entropy values easily separated each size accurately for both modal and harmonic characteristics.

The WSHE and WLEE results for the frequency of various crack sizes at different depths at a fixed crack position of $150 \mathrm{~mm}$ are illustrated in Figures 13 and 14, respectively. The values of both WSHE and WLEE accurately distinguished the modal and harmonic characteristics. Again, the entropy values were easily able to separate each size accurately for both modal and harmonic characteristics. Comparing the results obtained, the wavelet entropies calculated for the $75 \mathrm{~mm}$ position were different from those calculated for the fixed position of $150 \mathrm{~mm}$.

The WSHE and WLEE results for the frequency of various crack sizes at different depths at a fixed crack position of $225 \mathrm{~mm}$ are illustrated in Figures 15 and 16, respectively. Again, the values of both WSHE and WLEE accurately distinguished the modal and harmonic characteristics and the entropy values were able to separate each size accurately for both modal and harmonic characteristics. Comparing the results obtained, the wavelet entropies calculated for the fixed crack position of $75 \mathrm{~mm}$ were different from those calculated for the fixed crack positions of 150 and $225 \mathrm{~mm}$.

Cantilever beams with one crack were examined to compare the experimental results and theoretical predictions (Table 5). The accuracy of theoretical predictions was good, but the accuracy was lower to predict the crack size. The maximum absolute error was 7.5\% for the crack position and 9.1\% for the crack size. A crack for long beam-like structures can be instantly located by effectively predicting the position.

The sensitivity of the damage vibration diagnostics to environmental conditions was one of the constraints in damage vibration diagnostics due to moisture and temperature. Modifications in the signal amplitude were caused by the effects of temperature on the features of sensor and actuator because of changes in temperature.

Gorgin et al. [62] stated that modifications in transducer features might become more considerable for large temperature impairments. On the contrary, the selection of 
TABLE 3: The WSHE and WLEE results for the vibration frequency calculated for different depths and positions of an $18 \mathrm{~mm}$ crack.

\begin{tabular}{|c|c|c|c|c|c|c|}
\hline \multirow{2}{*}{ Position (mm) } & \multicolumn{3}{|c|}{ Modal } & \multicolumn{3}{|c|}{ Harmonic } \\
\hline & Depth (mm) & Frequency $(\mathrm{Hz})$ & WSHE/WLEE & Amplitude (mm) & Frequency $(\mathrm{Hz})$ & WSHE/WLEE \\
\hline \multirow{7}{*}{60} & 1.6 & 14.783 & & 39.229 & 14.78 & $-7.8792 e+03$ \\
\hline & 3.2 & 14.766 & & 39.309 & 14.76 & 37.4384 \\
\hline & 4.8 & 14.740 & - & 39.439 & 14.74 & \\
\hline & 11.2 & 14.482 & $-7.8825 e+03$ & 40.760 & 14.48 & \\
\hline & 12.8 & 14.413 & 37.4409 & 41.128 & 14.41 & \\
\hline & 14.4 & 14.373 & & 41.339 & 14.37 & \\
\hline & 16.0 & 13.981 & & 43.535 & 13.98 & \\
\hline \multirow{7}{*}{100} & 1.6 & 14.785 & & 39.220 & 14.78 & \\
\hline & 3.2 & 14.776 & - & 39.277 & 14.77 & $-8.0246 e+03$ \\
\hline & 4.8 & 14.760 & $-9.2084 e+03$ & 39.370 & 14.76 & 37.5499 \\
\hline & 11.2 & 14.610 & 42.9416 & 40.297 & 14.61 & \\
\hline & 12.8 & 14.565 & & 40.584 & 14.56 & \\
\hline & 14.4 & 14.547 & & 40.694 & 14.54 & \\
\hline & 16.0 & 14.309 & & 42.244 & 14.30 & \\
\hline \multirow{7}{*}{120} & 1.6 & 14.786 & & 39.217 & 14.78 & \\
\hline & 3.2 & 14.779 & - & 39.262 & 14.77 & $-8.0835 e+03$ \\
\hline & 4.8 & 14.769 & $-7.8825 e+03$ & 39.336 & 14.76 & 37.5940 \\
\hline & 11.2 & 14.661 & 37.4409 & 40.086 & 14.66 & \\
\hline & 12.8 & 14.627 & & 40.321 & 14.62 & \\
\hline & 14.4 & 14.615 & & 40.409 & 14.61 & \\
\hline & 16.0 & 14.442 & & 41.652 & 14.44 & \\
\hline \multirow{7}{*}{160} & 1.6 & 14.788 & - & 39.209 & 14.78 & \\
\hline & 3.2 & 14.785 & $-9.2084 e+03$ & 39.236 & 14.78 & $-8.1748 e+03$ \\
\hline & 4.8 & 14.781 & 42.9416 & 39.277 & 14.78 & 37.6610 \\
\hline & 11.2 & 14.735 & & 39.709 & 14.73 & \\
\hline & 12.8 & 14.720 & & 39.846 & 14.72 & \\
\hline & 14.4 & 14.715 & & 39.901 & 14.71 & \\
\hline & 16.0 & 14.639 & & 40.615 & 14.63 & \\
\hline \multirow{7}{*}{200} & 1.6 & 14.788 & - & 39.205 & 14.78 & $-8.2236 e+03$ \\
\hline & 3.2 & 14.788 & $-8.2304 e+03$ & 39.215 & 14.78 & 37.6964 \\
\hline & 4.8 & 14.787 & 37.7012 & 39.236 & 14.78 & \\
\hline & 11.2 & 14.775 & & 39.428 & 14.77 & \\
\hline & 12.8 & 14.771 & & 39.487 & 14.77 & \\
\hline & 14.4 & 14.770 & & 39.514 & 14.77 & \\
\hline & 16.0 & 14.747 & & 39.834 & 14.74 & \\
\hline
\end{tabular}

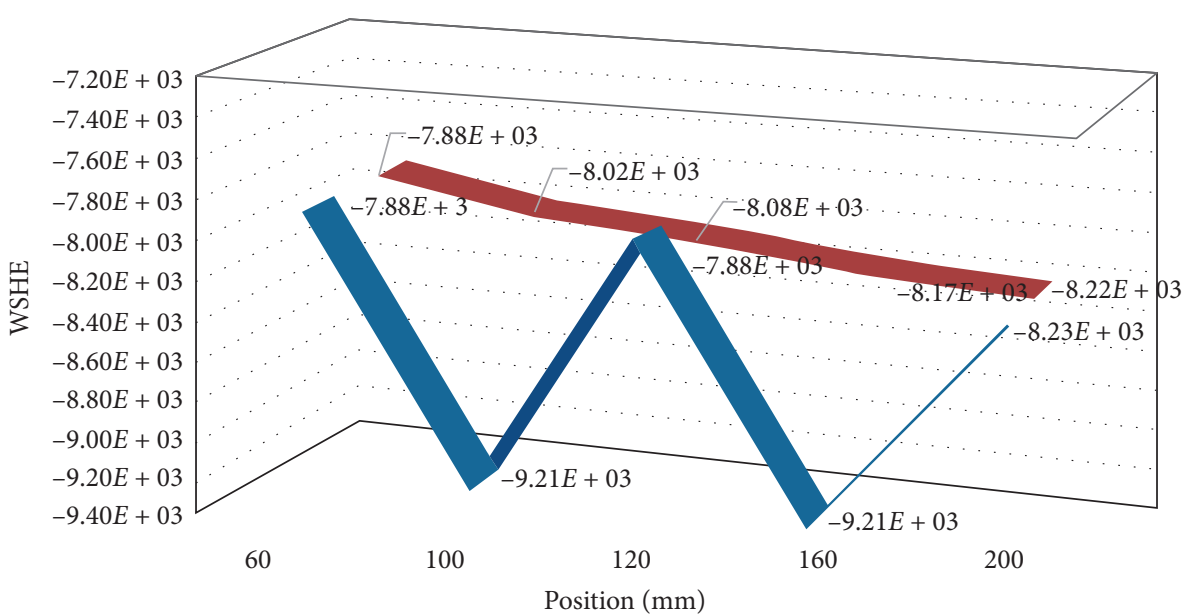

Figure 9: The WSHE results for frequency for a crack size of $18 \mathrm{~mm}$ at different positions. 


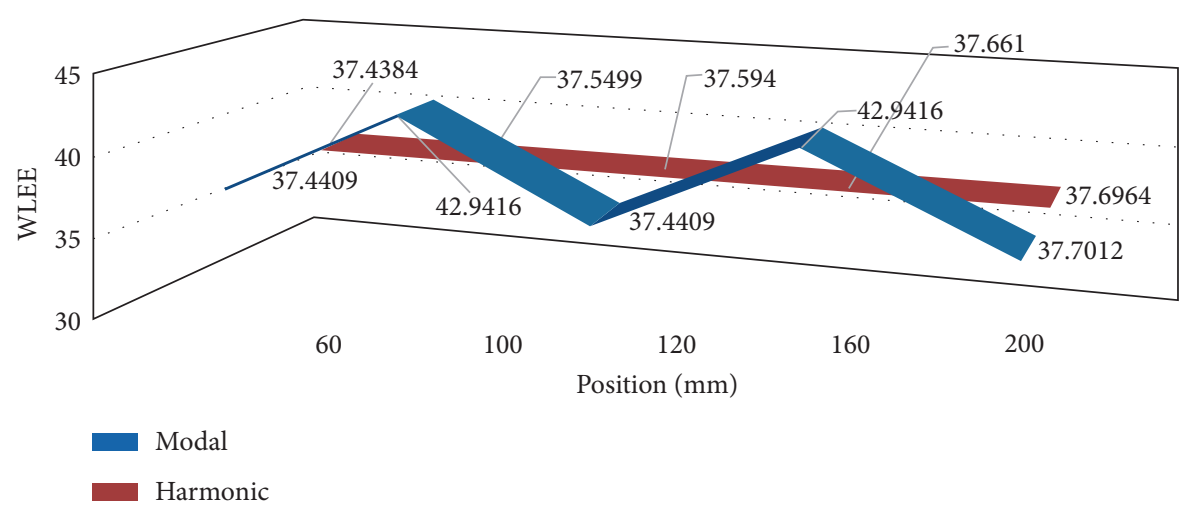

FIgURE 10: The WLEE results for frequency for a crack size of $18 \mathrm{~mm}$ at different positions.

TABLE 4: The WSHE and WLEE results for the vibration frequency calculated for different depths at each crack size.

\begin{tabular}{|c|c|c|c|c|c|c|}
\hline \multirow{2}{*}{ Depth (mm) } & \multicolumn{3}{|c|}{ Modal } & \multicolumn{3}{|c|}{ Harmonic } \\
\hline & Size $(\mathrm{mm})$ & Frequency $(\mathrm{Hz})$ & WSHE/WLEE & Amplitude (mm) & Frequency $(\mathrm{Hz})$ & WSHE/WLEE \\
\hline 1.6 & & 14.787 & $-8.1116 e+03$ & 39.211 & 14.78 & $-8.1020 e+03$ \\
\hline 3.2 & & 14.778 & 37.6147 & 39.256 & 14.77 & 37.6078 \\
\hline 4.8 & & 14.766 & & 39.319 & 14.76 & \\
\hline 11.2 & 12 & 14.669 & & 39.840 & 14.66 & \\
\hline 12.8 & & 14.649 & & 39.948 & 14.64 & \\
\hline 14.4 & & 14.643 & & 39.982 & 14.64 & \\
\hline 16.0 & & 14.499 & & 40.780 & 14.49 & \\
\hline 1.6 & & 14.786 & $-8.0636 e+03$ & 39.214 & 14.78 & \\
\hline 3.2 & & 14.776 & 37.5791 & 39.268 & 14.77 & $-7.8556 e+03$ \\
\hline 4.8 & & 14.761 & & 39.348 & 14.61 & 37.4103 \\
\hline 11.2 & 14 & 14.630 & & 40.029 & 14.63 & \\
\hline 12.8 & & 14.599 & & 40.224 & 14.59 & \\
\hline 14.4 & & 14.588 & & 40.283 & 14.58 & \\
\hline 16.0 & & 14.392 & & 41.387 & 13.39 & \\
\hline 1.6 & & 14.785 & & 39.219 & 14.78 & \\
\hline 3.2 & & 14.774 & $-8.0080 e+03$ & 39.279 & 14.77 & $-8.0026 e+03$ \\
\hline 4.8 & & 14.755 & 37.5373 & 39.378 & 14.75 & 37.5333 \\
\hline 11.2 & 16 & 14.587 & & 40.292 & 14.58 & \\
\hline 12.8 & & 14.541 & & 40.544 & 14.54 & \\
\hline 14.4 & & 14.523 & & 40.643 & 14.52 & \\
\hline 16.0 & & 14.264 & & 42.130 & 14.26 & \\
\hline 1.6 & & 14.784 & $-7.9422 e+03$ & 39.223 & 14.78 & $-7.9370 e+03$ \\
\hline 3.2 & & 14.771 & 37.4871 & 39.294 & 14.77 & 37.4832 \\
\hline 4.8 & & 14.749 & & 39.408 & 14.74 & \\
\hline 11.2 & 18 & 14.537 & & 40.568 & 14.53 & \\
\hline 12.8 & & 14.471 & & 40.940 & 14.47 & \\
\hline 14.4 & & 14.443 & & 41.096 & 14.44 & \\
\hline 16.0 & & 14.113 & & 43.036 & 14.11 & \\
\hline 1.6 & & 14.783 & $-7.8641 e+03$ & 39.229 & 14.78 & $-7.8577 e+03$ \\
\hline 3.2 & & 14.767 & 37.4264 & 39.315 & 14.76 & 37.4215 \\
\hline 4.8 & & 14.742 & & 39.446 & 14.74 & \\
\hline 11.2 & 20 & 14.478 & & 40.900 & 14.47 & \\
\hline 12.8 & & 14.385 & & 41.426 & 14.38 & \\
\hline 14.4 & & 14.347 & & 41.650 & 14.34 & \\
\hline 16.0 & & 13.933 & & 44.153 & 13.93 & \\
\hline
\end{tabular}




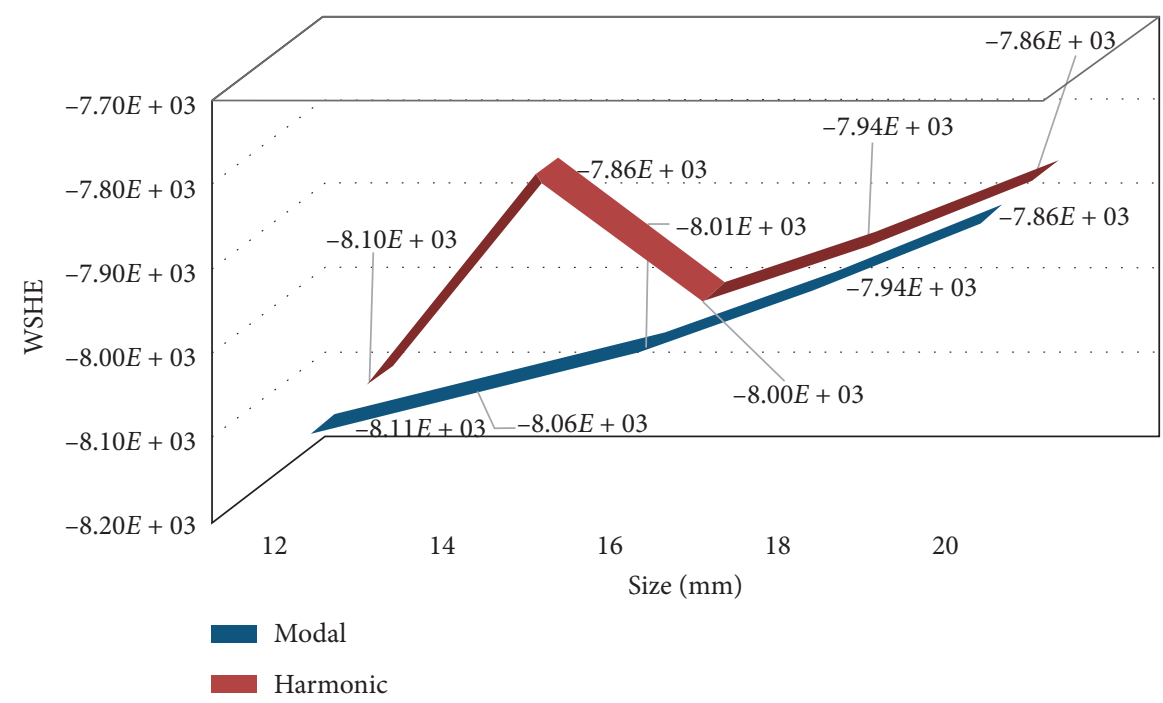

FIgURE 11: Variation in WSHE for the frequency and amplitude of different sized cracks at a crack position of $75 \mathrm{~mm}$.

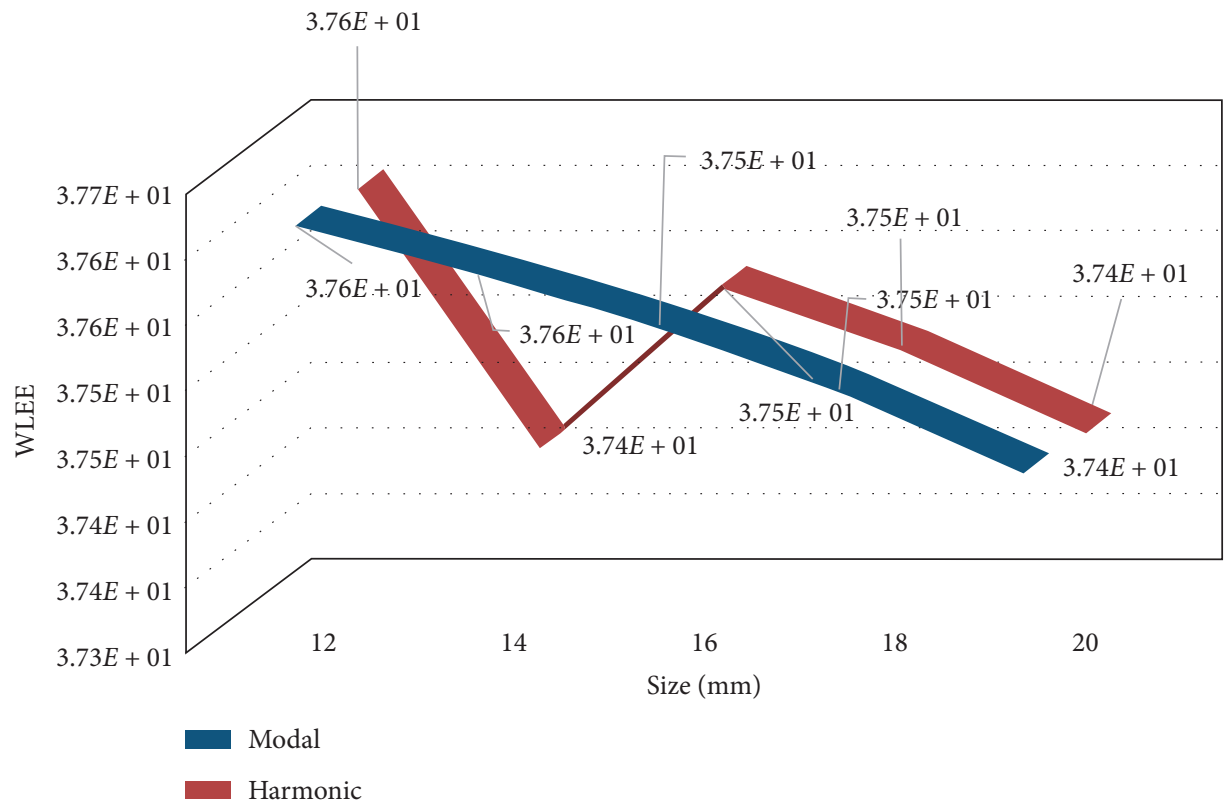

FigURE 12: Variation in WLEE for the frequency and amplitude of different sized cracks for a crack position of $75 \mathrm{~mm}$.

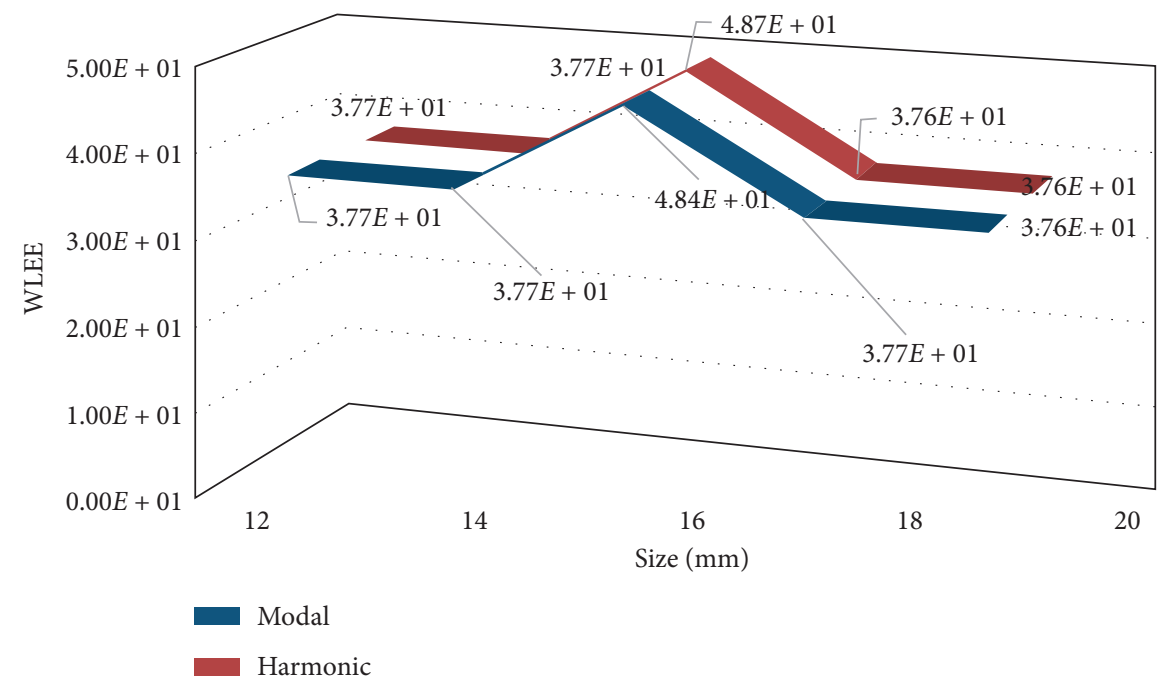

FIGURE 13: Variation in WLEE for the frequency and amplitude of different sized cracks at a crack position of $150 \mathrm{~mm}$. 


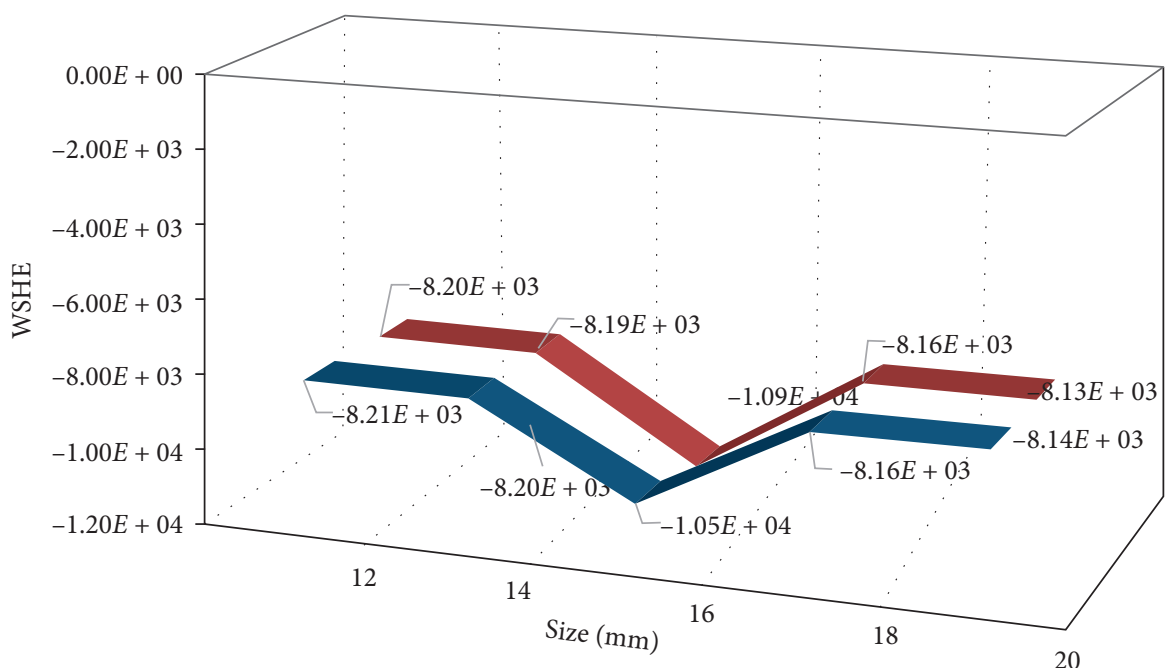

Modal

Harmonic

FIGURE 14: Variation in WSHE for the frequency of different sized cracks at a crack position of $150 \mathrm{~mm}$ at different depths.
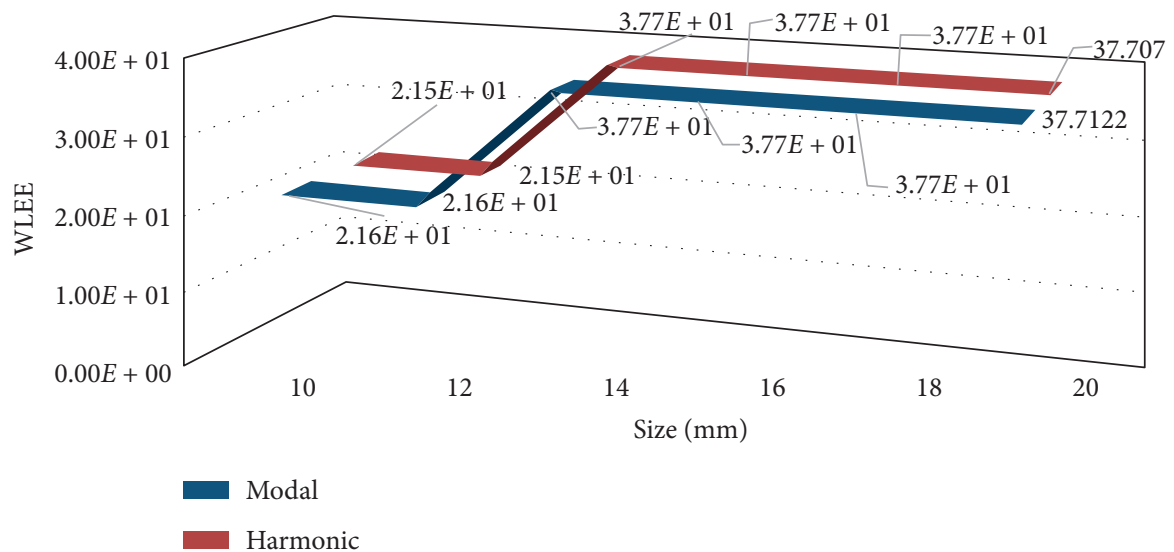

FIGURE 15: Variation in WLEE for the frequency and amplitude for different sized cracks at a crack position of $225 \mathrm{~mm}$ at different depths.

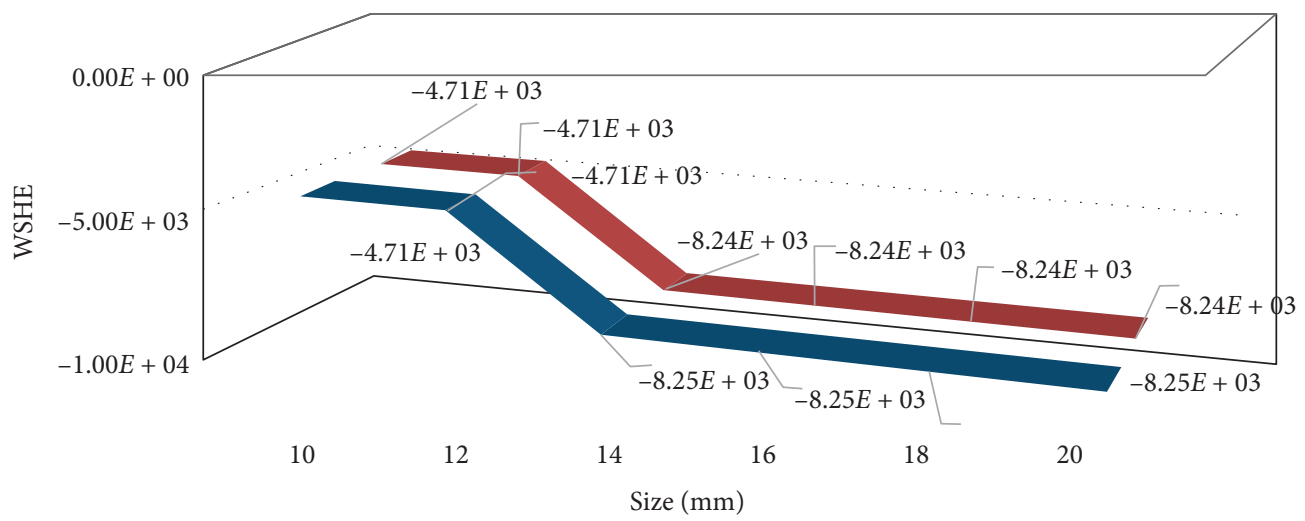

Modal

Harmonic

FIGURE 16: Variation in WSHE for the frequency and amplitude of different sized cracks at a crack position of $225 \mathrm{~mm}$ at different depths. 
TABLE 5: The absolute errors obtained when comparing the actual and predicted crack positions and sizes for cantilever beams.

\begin{tabular}{lccc}
\hline Crack position $(\mathrm{mm})$ & Absolute error $(\%)$ & Crack size $(\mathrm{mm})$ & Absolute error $(\%)$ \\
\hline 60 & 7.5 & 12 & 1.6 \\
100 & 5.1 & 14 & 3.1 \\
120 & 3.4 & 16 & 4.3 \\
160 & 2.2 & 18 & 7.2 \\
200 & 1.2 & 20 & 9.1 \\
\hline
\end{tabular}

appropriate transducer manufacturers, types, and materials can reduce this change [62]. Surace and Bovsunovsky [63] have mentioned that by increasing the temperature from -20 to $50^{\circ} \mathrm{C}$, Young's modulus of metallic structures decreased almost linearly by $1 \%$. Therefore, it is presumed that the impact of temperature on the standard observations of metal structures can be ignored. As for the effect of moisture, Sateesh et al. [64] showed that moisture generally affects any property of a composite material that is dominated by the matrix. However, the effect of change in moisture content on wave propagation is less important in metallic structures as compared to the composite features since moisture influences the adhesive and transducer layer in metallic structures. As stated in Surace and Bovsunovsky [63], "as the value of Young's modulus for steel is imperceptibly dependent on the presence of rain or humidity of air, it can be presumed that natural frequencies of steel structures do not depend that much on those factors in comparison with natural frequencies of concrete bridge structures." Erazo et al. [65] recommended that specific environmental impacts tend to elevate changes that influence all the vibration features in a standard process. However, the structure is locally affected by structural damages and, in turn, influences substantially the vibration modes.

According to the results, the methodology presented in this study provides a simple and quick method to determine the position and size of a crack in a cantilever beam with one crack at an acceptable accuracy level. This study shows that the combination of using wavelet transform and entropy is an amazing measure for removing the randomness in the data. One of the contributions of this study is the usage of wavelet transform, which can decompose a signal into different frequency band passes, so that each specific frequency band pass can be discussed separately. Another contribution of this study is the usage of entropy, which makes the results very specific as they are based only on one number. Furthermore, this study used the wavelet-entropy combination to detect cracks in beams for the first time. The research on damage detection in structures on the basis of vibration measurements is still underway by the authors. For the same reason, this research is expected to open new doors for utilizing wavelet transform technology in structural mechanics and composite communities.

\section{Conclusions}

The existence of a crack in a structure has an effect on its stiffness and influences its frequency. In this study, the obtained results showed that the stiffness of a beam decreases when the crack depth increases, which, consequently, reduces its standard observations. The crack position along with the length of the beam also affects its stiffness. The lowest stiffness and frequency of the beam were obtained when the crack was within the beam in contrast with the observations obtained when the crack was at the far end of the beam. Furthermore, an elevation in the crack size affected both the amplitude and frequency of the structure. As the crack size increased, the vibrational amplitude of the beam decreased. The results showed that with increase in crack depth, the amplitude also increased at certain crack sizes and for all crack positions. For two crack depths of $1.6 \mathrm{~mm}$ and $0.16 \mathrm{~mm}$ having the same crack size and position $12 \mathrm{~mm}$ and $60 \mathrm{~mm}$, respectively, a $4.5 \%$ increase in amplitude was observed at a crack depth of $1.6 \mathrm{~mm}$. Moreover, the amplitude varied inversely with the position. A $12.6 \%$ increase in amplitude was observed at a crack depth of $1.6 \mathrm{~mm}$ rather than $0.16 \mathrm{~mm}$, while both depths occurred at the same crack position $(75 \mathrm{~mm})$ and size $(20 \mathrm{~mm})$. This dependence of the beam's frequency and amplitude on various characteristics of the crack reveals the possibility that this technique can successfully determine the crack size in a structure through measuring its frequency and amplitude. For the detection of beam crack dimensions, such as the depth, size, and position, two types of the wavelet entropies, Shannon and log energy, were suggested and implemented. Because of the possibilities of dividing the data into different frequency band passes via wavelet packet, results of the calculated entropy over these band passes could accurately recognize the beam crack dimensions over the modal and harmonic characteristics. The experimental results and theoretical predictions were compared, and the accuracy of predictions obtained using this method was acceptable. The maximum absolute error found was $7.5 \%$ for the crack position and $9.1 \%$ for the crack size.

\section{Data Availability}

The datasets used and analyzed during the current study are available from the corresponding author on reasonable request.

\section{Conflicts of Interest}

The authors declare that there are no conflicts of interest.

\section{Acknowledgments}

This project was funded by the Deanship of Scientific Research (DSR) at King Abdulaziz University, Jeddah under grant no. G-1440-135-1440. The author, therefore, acknowledges with thanks DSR for their technical and financial support. 


\section{References}

[1] R. Janeliukstis, S. Rucevskis, M. Wesolowski, and A. Chate, "Experimental structural damage localization in beam structure using spatial continuous wavelet transform and mode shape curvature methods," Measurement, vol. 102, pp. 253-270, 2017.

[2] H. Naderpour and P. Fakharian, "A synthesis of peak picking method and wavelet packet transform for structural modal identification," KSCE Journal of Civil Engineering, vol. 20, no. 7, pp. 2859-2867, 2016.

[3] J. Zhou, Z. Li, and J. Chen, "Damage identification method based on continuous wavelet transform and mode shapes for composite laminates with cutouts," Composite Structures, vol. 191, pp. 12-23, 2018.

[4] A. K. Pandey, M. Biswas, and M. M. Samman, "Damage detection from changes in curvature mode shapes," Journal of Sound and Vibration, vol. 145, no. 2, pp. 321-332, 1991.

[5] E. Parloo, P. Verboven, P. Guillaume, and M. Van Overmeire, "Autonomous structural health monitoring-part ii: vibrationbased in-operation damage assessment," Mechanical Systems and Signal Processing, vol. 16, no. 4, pp. 659-675, 2002.

[6] L. M. Khoo, P. R. Mantena, and P. Jadhav, "Structural damage assessment using vibration modal analysis," Structural Health Monitoring: An International Journal, vol. 3, no. 2, pp. 177194, 2004.

[7] R. P. C. Sampaio, N. M. M. Maia, and J. M. M. Silva, "Damage detection using the frequency-response-function curvature method," Journal of Sound and Vibration, vol. 226, no. 5, pp. 1029-1042, 1999.

[8] Y.S. Erdogan, "A study on the crack detection in beams using linear and nonlinear normal modes," Advances in Structural Engineering, vol. 23, no. 7, pp. 1305-1321, 2020.

[9] H. Fathnejat and B. Ahmadi-Nedushan, "An efficient twostage approach for structural damage detection using metaheuristic algorithms and group method of data handling surrogate model," Frontiers of Structural and Civil Engineering, vol. 14, pp. 1-23, 2020.

[10] G. Ludeno, N. Cavalagli, F. Ubertini, F. Soldovieri, and I. Catapano, "On the combined use of ground penetrating radar and crack meter sensors for structural monitoring: application to the historical consoli palace in gubbio, Italy," Surveys in Geophysics, vol. 41, pp. 1-21, 2019.

[11] D. Breysse, J. P. Balayssac, S. Biondi et al., "Recommendation of RILEM TC249-ISC on non destructive in situ strength assessment of concrete," Materials and Structures, vol. 52, no. 4, p. 71, 2019.

[12] S. Sfarra, C. Ibarra-Castanedo, D. Ambrosini, D. Paoletti, A. Bendada, and X. Maldague, "Discovering the defects in paintings using non-destructive testing (NDT) techniques and passing through measurements of deformation," Journal of Nondestructive Evaluation, vol. 33, no. 3, pp. 358-383, 2014.

[13] C. Kyriazoglou, B. H. Le Page, and F. J. Guild, "Vibration damping for crack detection in composite laminates," Composites Part A: Applied Science and Manufacturing, vol. 35, no. 7, pp. 945-953, 2004.

[14] B. Binici, "Vibration of beams with multiple open cracks subjected to axial force," Journal of Sound and Vibration, vol. 287, no. 1, pp. 277-295, 2005.

[15] A. D. Dimarogonas, "Vibration of cracked structures: a state of the art review," Engineering Fracture Mechanics, vol. 55, no. 5, pp. 831-857, 1996.

[16] D. P. Patil and S. K. Maiti, "Experimental verification of a method of detection of multiple cracks in beams based on frequency measurements," Journal of Sound and Vibration, vol. 281, no. 1, pp. 439-451, 2005.

[17] M.-H. H. Shen and J. E. Taylor, "An identification problem for vibrating cracked beams," Journal of Sound and Vibration, vol. 150 , no. 3, pp. 457-484, 1991.

[18] S. Masoud, M. A. Jarrah, and M. Al-Maamory, "Effect of crack depth on the natural frequency of a prestressed fixed-fixed beam," Journal of Sound and Vibration, vol. 214, no. 2, pp. 201-212, 1998.

[19] R. Y. Liang, F. K. Choy, and J. Hu, "Detection of cracks in beam structures using measurements of natural frequencies," Journal of the Franklin Institute, vol. 328, no. 4, pp. 505-518, 1991.

[20] Y. Narkis, "Identification of crack location in vibrating simply supported beams," Journal of Sound and Vibration, vol. 172, no. 4, pp. 549-558, 1994.

[21] M. H. Dado, "A comprehensive crack identification algorithm for beams under different end conditions," Applied Acoustics, vol. 51, no. 4, pp. 381-398, 1997.

[22] J. Hu and R. Y. Liang, "An integrated approach to detection of cracks using vibration characteristics," Journal of the Franklin Institute, vol. 330, no. 5, pp. 841-853, 1993.

[23] P. R. Baviskar and V. B. Tungikar, "Multiple cracks assessment using natural frequency measurement and prediction of crack properties by artificial neural network," International Journal of Advanced Science and Technology, vol. 54, pp. 23-38, 2013.

[24] M. Kisa, J. Brandon, and M. Topcu, "Free vibration analysis of cracked beams by a combination of finite elements and component mode synthesis methods," Computers \& Structures, vol. 67, no. 4, pp. 215-223, 1998.

[25] L. L. Fischer and G. E. Beltz, "Effect of crack geometry on dislocation nucleation and cleavage thresholds," in Materials Research Society Symposium Proceedings, pp. 57-62, Materials Research Society, Pittsburgh, PA, USA, 1999.

[26] A. S. Sekhar, "Multiple cracks effects and identification," Mechanical Systems and Signal Processing, vol. 22, no. 4, pp. 845-878, 2008.

[27] K. Mazanoglu, I. Yesilyurt, and M. Sabuncu, "Vibration analysis of multiple-cracked non-uniform beams," Journal of Sound and Vibration, vol. 320, no. 4, pp. 977-989, 2009.

[28] N. T. Khiem and T. V. Lien, "A simplified method for natural frequency analysis of a multiple cracked beam," Journal of Sound and Vibration, vol. 245, no. 4, pp. 737-751, 2001.

[29] A. Banerjee, G. Pohit, and B. Panigrahi, "Vibration analysis and prediction natural frequencies of cracked timoshenko beam by two optimization techniques-cascade ANN and ANFIS," Materials Today: Proceedings, vol. 4, no. 9, pp. 9909-9913, 2017.

[30] S. Ahmad, A. Waleed, U. S. Virk, M. T. Riaz, A. Sharjeel, and N. Ahmad, "Multiple damage detections in plate-like structures using curvature mode shapes and gapped smoothing method," Advances in Mechanical Engineering, vol. 11, no. 5, 2019.

[31] V. Khalkar and S. Ramachandran, "Free vibration study of v-shape and rectangular shape double-sided cracks in a cantilever beam," Journal of Vibroengineering, vol. 19, no. 2, pp. 1026-1038, 2017.

[32] M. Dahak, N. Touat, and T. Benkedjouh, "Crack detection through the change in the normalized frequency shape," Vibration, vol. 1, no. 1, pp. 56-68, 2018.

[33] M. U. Hanif, Z. Ibrahim, K. Ghaedi, H. Hashim, and A. Javanmardi, "Damage assessment of reinforced concrete structures using a model-based nonlinear approach-a 
comprehensive review," Construction and Building Materials, vol. 192, pp. 846-865, 2018.

[34] I. Matsko, I. Javorskyj, R. Yuzefovych, and Z. Zakrzewski, "Forced oscillations of cracked beam under the stochastic cyclic loading," Mechanical Systems and Signal Processing, vol. 104, pp. 242-263, 2018.

[35] J. Prawin, K. Lakshmi, and A. Rama Mohan Rao, "A novel vibration based breathing crack localization technique using a single sensor measurement," Mechanical Systems and Signal Processing, vol. 122, pp. 117-138, 2019.

[36] M. Jiang, W. Zhang, and Q. Lu, "A nonlinearity measurebased damage location method for beam-like structures," Measurement, vol. 146, pp. 571-581, 2019.

[37] M. Maurya, R. Mishra, and I. Panigrahi, "Multi crack detection in structures using artificial neural network," IOP Conference Series Materials Science and Engineering, vol. 402, 2018.

[38] K. H. Padil, N. Bakhary, M. Abdulkareem, J. Li, and H. Hao, "Non-probabilistic method to consider uncertainties in frequency response function for vibration-based damage detection using artificial neural network," Journal of Sound and Vibration, vol. 467, Article ID 115069, 2020.

[39] X. Teng, X. Zhang, Y. Fan, and D. Zhang, "Evaluation of cracks in metallic material using a self-organized data-driven model of acoustic echo-signal," Applied Sciences, vol. 9, no. 1, p. 95, 2019.

[40] S. De Lellis, A. Stabile, G. S. Aglietti, and G. Richardson, "Structural uncertainty estimation through a craig-bampton stochastic method optimisation in satellites structures," Journal of Sound and Vibration, vol. 469, Article ID 115123, 2020.

[41] A. J. Choi and J.-H. Han, "Frequency-based damage detection in cantilever beam using vision-based monitoring system with motion magnification technique," Journal of Intelligent $\mathrm{Ma}$ terial Systems and Structures, vol. 29, no. 20, pp. 3923-3936, 2018.

[42] K. Daqrouq and M. Ajour, "The use of LPC and wavelet transform for influenza disease modeling," Entropy, vol. 20, no. 8, p. 590, 2018.

[43] K. Daqrouq, H. Sweidan, A. Balamesh, and M. Ajour, "Offline handwritten signature recognition by wavelet entropy and neural network," Entropy, vol. 19, no. 6, p. 252, 2017.

[44] C.-C. Chang and L.-W. Chen, "Detection of the location and size of cracks in the multiple cracked beam by spatial wavelet based approach," Mechanical Systems and Signal Processing, vol. 19, no. 1, pp. 139-155, 2005.

[45] C. C. Chang, S. M. Chang, H. Y. Huang, and J. Y. Yeh, "Application of the wavelet analysis to strain energy damage detection method," Journal of Professional Mechanical Engineers, vol. 1, no. 1, pp. 1-4, 2008.

[46] A. H. Zamanian and A. Ohadi, "Crack identification in timoshenko beam using local maxima lines of wavelet coefficients," in Proceedings of the 16th International Congress on Sound and Vibration 2009, pp. 5-9, Krakow, Poland, July 2009.

[47] M. Gómez, E. Corral, C. Castejón, and J. García-Prada, "Effective crack detection in railway axles using vibration signals and WPT energy," Sensors, vol. 18, no. 5, p. 1603, 2018.

[48] S. G. Mallat, "A theory for multiresolution signal decomposition: the wavelet representation," IEEE Transactions on Pattern Analysis and Machine Intelligence, vol. 11, no. 7, pp. 674-693, 1989.

[49] C. Souani, M. Abid, K. Torki, and R. Tourki, "VLSI design of 1-D DWT architecture with parallel filters," Integration, vol. 29, no. 2, pp. 181-207, 2000.
[50] A. Ghaffari, H. Golbayani, and M. Ghasemi, "A new mathematical based QRS detector using continuous wavelet transform," Computers \& Electrical Engineering, vol. 34, no. 2, pp. 81-91, 2008.

[51] A. S. More, "Vibration analysis of cracked cantilever beam-a review," 2016.

[52] D. Avci, "An expert system for speaker identification using adaptive wavelet sure entropy," Expert Systems with Applications, vol. 36, no. 3, pp. 6295-6300, 2009.

[53] T. D. Ganchev, D. K. Tasoulis, M. N. Vrahatis, and N. D. Fakotakis, "Generalized locally recurrent probabilistic neural networks with application to text-independent speaker verification," Neurocomputing, vol. 70, no. 7-9, pp. 1424-1438, 2007.

[54] Z.-B. Yang, M. Radzienski, P. Kudela, and W. Ostachowicz, "Damage detection in beam-like composite structures via chebyshev pseudo spectral modal curvature," Composite Structures, vol. 168, pp. 1-12, 2017.

[55] Z.-B. Yang, M. Radzienski, P. Kudela, and W. Ostachowicz, "Two-dimensional chebyshev pseudo spectral modal curvature and its application in damage detection for composite plates," Composite Structures, vol. 168, pp. 372-383, 2017.

[56] H. Laouira, F. Mebarek-Oudina, A. K. Hussein, L. Kolsi, A. Merah, and O. Younis, "Heat transfer inside a horizontal channel with an open trapezoidal enclosure subjected to a heat source of different lengths," Heat Transfer-Asian Research, vol. 49, no. 1, pp. 406-423, 2020.

[57] S. Marzougui, F. Mebarek-Oudina, A. Aissa, M. Magherbi, Z. Shah, and K. Ramesh, "Entropy generation on magnetoconvective flow of copper-water nanofluid in a cavity with chamfers," Journal of Thermal Analysis and Calorimetry, 2020.

[58] F. Mebarek-Oudina, A. Aissa, B. Mahanthesh, and H. F. Öztop, "Heat transport of magnetized newtonian nanoliquids in an annular space between porous vertical cylinders with discrete heat source," International Communications in Heat and Mass Transfer, vol. 117, Article ID 104737, 2020.

[59] ANSYS, ANSYS Meshing User's Guide, ANSYS, Canonsburg, PA, USA, 2014.

[60] A. Entezami, H. Sarmadi, and B. S. Razavi, "An innovative hybrid strategy for structural health monitoring by modal flexibility and clustering methods," Journal of Civil Structural Health Monitoring, vol. 10, pp. 1-15, 2020.

[61] P. S. Sánchez, P. L. Negro, and P. García-Fogeda, "Vibrationbased method for damage detection at welded beams and rods," Latin American Journal of Solids and Structures, vol. 13, no. 13, pp. 2336-2355, 2016.

[62] R. Gorgin, Y. Luo, and Z. Wu, "Environmental and operational conditions effects on lamb wave based structural health monitoring systems: a review," Ultrasonics, vol. 105, Article ID 106114, 2020.

[63] C. Surace and A. Bovsunovsky, "The use of frequency ratios to diagnose structural damage in varying environmental conditions," Mechanical Systems and Signal Processing, vol. 136, Article ID 106523, 2020.

[64] N. Sateesh, P. S. Rao, D. V. Ravishanker, and K. Satyanarayana, "Effect of moisture on GFRP composite materials," Materials Today: Proceedings, vol. 2, no. 4, pp. 2902-2908, 2015.

[65] K. Erazo, D. Sen, S. Nagarajaiah, and L. Sun, "Vibration-based structural health monitoring under changing environmental conditions using kalman filtering," Mechanical Systems and Signal Processing, vol. 117, pp. 1-15, 2019. 